\title{
Soluble intercellular adhesion molecule-1 in the bronchoalveolar lavage fluid of normal children exposed to parental cigarette smoke
}

\author{
J. Grigg, J. Riedler, C.F. Robertson
}

\begin{abstract}
Soluble intercellular adhesion molecule-1 in the bronchoalveolar lavage fluid of normal children exposed to parental cigarette smoke. J. Grigg, J. Riedler, C.F. Robertson. (C)ERS Journals Ltd 1999.

ABSTRACT: This study sought to test the hypothesis that normal children exposed to parental cigarette smoke have increased bronchoalveolar lavage (BAL) fluid levels of soluble intercellular adhesion molecule (sICAM)-1.

Cells and solutes from the lower airway of normal children were obtained by nonbronchoscopic BAL using three aliquots of $1 \mathrm{~mL} \cdot \mathrm{kg}$ body weight ${ }^{-1}$ normal saline, prior to elective orthopaedic surgery. Children with evidence of recent or ongoing infection, atopic disease, previous history of wheeze, and chronic respiratory symptoms were excluded. Twelve children with parents who smoked (group 1) were paired with 12 age- and weight-matched controls with self-reported nonsmoking parents (group 2).

There was no significant difference (group 1 versus 2 ) in the volume of BAL fluid recovered (median 29.0 versus $28.7 \mathrm{~mL}$ ), the percentage of alveolar macrophages $(92.5$ versus $91.8 \%$ ), neutrophils (1.1 versus $2.1 \%)$, lymphocytes $(5.3$ versus $5.6 \%)$ and eosinophils (0 versus $0 \%$ ), and the total BAL fluid leukocyte concentration (80 versus $61 \times 10^{3}$ cells $\left.\cdot \mathrm{mL}^{-1}\right)$. BAL fluid albumin concentration was similar between the two groups $\left(0.033\right.$ versus $\left.0.020 \mathrm{mg} \cdot \mathrm{mL}^{-1}\right)$. sICAM-1 was detected in all BAL fluid samples, and was significantly increased in group $1\left(39.2\right.$ versus $\left.22.5 \mathrm{ng} \cdot \mathrm{mL}^{-1}, \mathbf{p}<0.01\right)$.

It was concluded that exposure of children to parental cigarette smoke is associated with increased soluble intercellular adhesion molecule-1 concentrations in the bronchoalveolar lavage fluid and this may reflect an altered activation of pulmonary immune cells.
\end{abstract}

Eur Respir J 1999; 13: 810-813.

Dept of Thoracic Medicine, Royal Children's Hospital, Melbourne, Victoria, Australia.

Correspondence: J. Grigg

The Leicester Children's Asthma Centre University of Leicester

PO Box 65

Leicester LE2 7LX

UK

Fax: 441162523282

Keywords: Bronchoalveolar lavage children

smoking

soluble intercellular adhesion molecule-1

Received: September 31998

Accepted after revision January 111999
Postnatal exposure of children to parental cigarette smoke is strongly associated with an increased prevalence of acute lower respiratory symptoms in infants [1], and wheeze, cough, phlegm and breathlessness in school-age children [2]. The mechanisms whereby parental cigarette smoke increases the vulnerability of the normal lung to respiratory disease are unknown. There have been two studies of the lower respiratory tract milieu of children exposed to environmental cigarette smoke. HeANEY et al. [3] performed nonbronchoscopic bronchoalveolar lavage (BAL) on children prior to elective surgery, and found no alteration in the BAL fluid leukocyte differential in association with parent-reported cigarette smoking. Using fibreoptic BAL of normal children prior to surgery, RATJEN et al. [4] also found no change in the BAL fluid leukocyte differential or leukocyte concentration with parental smoking. The majority of BAL studies in adults found that smokers had an increased alveolar macrophage (AM) differential $[5,6]$. Active smoking also influences markers of pulmonary cell function. These include increased AM expression of $\beta_{2}$ integrins CD11a, CD11b, CD11c/18 [7], and an altered pattern of cytokines in the BAL fluid [8]. Similarly, passive inhalation of parental cigarette smoke could be associated with pulmonary cell activation, without a concomitant change in the alveolar leukocyte profile.
Soluble intercellular adhesion molecule (sICAM)-1 in the alveolar epithelial lining fluid is a nonspecific marker of immune cell activation within the pulmonary microenvironment, and is increased in a variety of immune diseases including idiopathic pulmonary fibrosis and allergic inflammation [9-11]. It is formed by shedding from ICAM-1 expressing cells [12], including alveolar leukocytes [13]. Upregulation of pulmonary tissue ICAM-1 is therefore associated with increased sICAM-1 levels in the BAL fluid [14]. sICAM-1 levels are increased in the serum of adult smokers [15], suggesting that it is an important marker of cellular activation induced by cigarette smoke. In the present study, nonbronchoscopic BAL was used to recover alveolar epithelial lining fluid and cells from normal children undergoing elective surgery, in order to determine whether pulmonary sICAM-1 is related to parent-reported cigarette smoking.

Methods

Subjects

Children between 6 months and 18 yrs of age, intubated for elective orthopaedic surgery, were eligible for BAL. 
The exclusion criteria were premature birth, chronic respiratory pathology, chronic systemic disease, atopic symptoms, acute respiratory symptoms in the preceding 8 weeks, history of wheeze, and the isolation of a bacterial or viral pathogen from the BAL fluid. Exposure of the child to parental cigarette smoke was assessed by asking the caregiver(s), "do either you or your partner smoke?". To reduce false negative reporting, no further information about parental smoking was obtained. Children of smoking parents (group 1) were paired with age- and weight-matched children of self-reported nonsmoking parents (group 2 ). The study was approved by the Ethics in Human Research Committee of the Royal Children's Hospital and required written parental consent.

\section{Bronchoalveolar lavage}

BAL was performed before surgery by a single operator (J. Grigg) using a nonbronchoscopic BAL technique [16, 17]. Prior to elective surgery, children did not receive anticholinergic premedication. Anaesthesia was performed with isofluorane, intravenous thiopentone and pancuronium. Immediately after intubation, and with the child's head turned to the left, a straight $60 \mathrm{~cm}$ end-hole suction catheter (Vygon S.A., Écouen, France) was inserted into the endotracheal tube (ET) through a right-angle swivel bronchoscope connector (Mallinckrodt Medical Pty. Ltd., Mount Waverley, Australia). Catheter size was adjusted to the ET diameter $(6 \mathrm{~F}$ catheter for $\leq 3.5 \mathrm{~cm} \mathrm{ET}, 7 \mathrm{~F}$ catheter for $3.5 \mathrm{~cm} \mathrm{ET,} 8 \mathrm{~F}$ catheter for $3.5-5.0 \mathrm{~cm} \mathrm{ET}, 10 \mathrm{~F}$ catheter for $\geq 5.5 \mathrm{~cm} \mathrm{ET)}$. The catheter was advanced until wedged, $1 \mathrm{~mL} \cdot \mathrm{kg}$ body weight ${ }^{-1}$ of saline at room temperature was instilled, and BAL fluid immediately aspirated into a suction trap using $20 \mathrm{kPa}$ negative pressure and a three-way tap. With the catheter remaining wedged in situ, two further aliquots of $1 \mathrm{~mL} \cdot \mathrm{kg}$ body weight ${ }^{-1}$ saline were instilled and aspirated (i.e. a total instilled volume of $3 \mathrm{~mL} \cdot \mathrm{kg}$ body weight ${ }^{-1}$ ). Pooled BAL fluid was placed on ice and $0.5 \mathrm{~mL}$ aliquots cultured for respiratory viruses, aerobic and anaerobic bacteria. All potential bacterial pathogens and commensals of the upper respiratory tract were identified and reported. Viral immunofluorescence was performed on cells concentrated by centrifugation. Immediately after collection, the concentration of leukocytes was determined by haemocytometer and viability determined by exclusion of a $0.04 \%$ solution of trypan blue. Ciliated epithelial cells in the haemocytometer chamber were not counted. Unfiltered BAL fluid was cytocentrifuged at $91 \times g$ for $5 \mathrm{~min}$ (Cytospin 2, Shandon Products Ltd, Runcorn, UK), stained with Wilson's reagents and examined under oil microscopy $(\times 1,000$ magnification). BAL fluid leukocyte differentials were determined by counting $\geq 300$ leukocytes. Particulate-free BAL fluid supernatant was obtained by centrifugation of unfiltered BAL fluid at $1,000 \times g$ for $10 \mathrm{~min}\left(4^{\circ} \mathrm{C}\right)$ and $8,000 \times g$ for a further $3 \mathrm{~min}\left(4^{\circ} \mathrm{C}\right)$. Aliquots of BAL fluid were stored at $-70^{\circ} \mathrm{C}$ for analysis of albumin and sICAM-1.

\section{BAL fluid albumin and SICAM-1}

The albumin assay was performed in duplicate samples of BAL fluid using a Roche Cobas centrifugal analyser
(Roche Diagnostics, Basel, Switzerland). Albumin was determined by immunoturbidometry with an assay linear dynamic range of $0.005-0.8 \mathrm{mg} \cdot \mathrm{mL}^{-1}$. The interassay coefficient of variation was $<9 \%$. sICAM- 1 was determined in duplicate BAL fluid samples using an enzyme-linked immunosorbent assay (ELISA) kit (Predicta B ICAM-1, Genzyme Diagnostics, Cambridge, MA, USA) with 1:10 and 1:50 dilutions of particulate-free BAL fluid. The assay sensitivity was $0.09 \mathrm{ng} \cdot \mathrm{mL}^{-1}$, with a linear dynamic range of $0.5-9.0 \mathrm{ng} \cdot \mathrm{mL}^{-1}$. The intra-assay coefficient of variation was $6.9 \%$.

\section{Statistical analysis}

Data from groups 1 and 2 were compared by Wilcoxon matched-pairs signed ranks test, and are summarized as median (25th, 75th percentile). Spearman's rank correlation (coefficient $r_{s}$ ) was used for univariate correlations. A value of $\mathrm{p}<0.05$ was considered significant throughout. Analysis was performed using a statistical package for

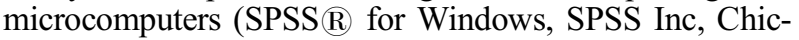
ago, IL, USA).

\section{Results}

Twelve children with parents who smoked (group 1) were matched with 12 children of nonsmoking parents (group 2). No child had respiratory symptoms in the preceding 8 weeks. There was no significant difference in age, weight, volume of saline instilled, and the volume of BAL fluid recovered between the two groups (table 1). BAL fluid leukocyte viability was $>95 \%$, and the proportion of nucleated cells that were ciliated epithelial cells was $<3 \%$. There were no differences between groups 1 and 2 for BAL fluid leukocyte differentials and concentrations, and for BAL fluid albumin concentration (table 2). sICAM-1 was detected in all BAL fluid samples, and in both groups the BAL fluid sICAM-1 concentration decreased with age $\left(r_{s}=-0.65, p<0.05\right.$, group 1 ; and $r_{s}=$ $-0.53, \mathrm{p}=0.06$, group 2). BAL fluid sICAM-1 was significantly greater in group $1(\mathrm{p}=0.007$, table 2 , fig. 1$)$.

\section{Discussion}

In the present study, the concentration of sICAM-1 in the BAL fluid of children exposed to cigarette smoke was

Table 1. - Clinical details and bronchoalveolar lavage dynamics in children with exposure to parental cigarette smoke (group 1) and with no exposure (group 2)

\begin{tabular}{lcc}
\hline & $\begin{array}{c}\text { Group 2 } \\
(\mathrm{n}=12)\end{array}$ & $\begin{array}{c}\text { Group 2 } \\
(\mathrm{n}=12)\end{array}$ \\
\hline Age months & $73.7(32,104)$ & $62.8(34,103)$ \\
Weight $\mathrm{kg}$ & $21.5(13,25)$ & $18.3(16,30)$ \\
Saline instilled $\mathrm{mL}$ & $62.7(40,75)$ & $54(40,81)$ \\
BALF aspirated $\mathrm{mL}$ & $29.0(22,44)$ & $28.7(20,43)$ \\
\hline
\end{tabular}

Values are shown as median (25th, 75 th percentiles). BALF: bronchoalveolar lavage fluid. Statistical assessment by Wilcoxon signed-ranks test. There was no significant difference between group 1 and group 2 for any variable. 
Table 2. - Bronchoalveolar lavage (BAL) fluid parameters in children with exposure to parental cigarette smoke (group 1) and nonexposed children (group 2)

\begin{tabular}{lcc}
\hline BAL fluid parameter & $\begin{array}{c}\text { Group 1 } \\
(\mathrm{n}=12)\end{array}$ & $\begin{array}{c}\text { Group 2 } \\
(\mathrm{n}=12)\end{array}$ \\
\hline Differential \% & & \\
Alveolar macrophage & $92.5(89,94)$ & $91.8(90,94)$ \\
Neutrophil & $1.1(0.7,2.6)$ & $2.1(1.0,2.8)$ \\
Lymphocyte & $5.3(4,7)$ & $5.6(4,8)$ \\
Eosinophil & $0(0,0.8)$ & $0(0,0.3)$ \\
Cell concentration & & \\
$\times 10^{3}$ cells·mL $L^{-1}$ & & \\
Total leukocyte & $80(52,140)$ & $61(42,100)$ \\
Alveolar macrophage & $74.4(46,129)$ & $53(38,94)$ \\
Neutrophil & $1.2(0.8,2.0)$ & $1.1(0.3,1.4)$ \\
Lymphocyte & $5.5(3,6)$ & $2.9(2,6)$ \\
Eosinophil & $0(0,0.5)$ & $0(0,0.1)$ \\
Albumin mg.mL $\mathrm{mL}^{-1}$ & $0.033(0.02,0.04)$ & $0.020(0.01,0.03)$ \\
sICAM-1 ng.mL $\mathrm{mL}^{-1}$ & $39.2(27,46)^{* *}$ & $22.5(20,28)$ \\
\hline
\end{tabular}

Values are shown as median (25th, 75 th percentiles). sICAM-1: soluble intercellular adhesion molecule-1. Statistical assessment by Wilcoxon signed-ranked test. **: $\mathrm{p}<0.01$ versus group 2 .

shown to be increased compared to children of nonsmoking parents. There is no accepted way of correcting for the dilution of alveolar epithelial lining by instilled saline, and the possibility that this observation is a technical artefact cannot be completely excluded. However, differences in dilution caused by differences in the dynamics of the instilled saline were minimized by using age- and weightmatched controls, and a weight-adjusted lavage volume. The use of age-matched controls was also important since sICAM-1 in other tissue compartments falls significantly with age [18]. The similar volume of BAL fluid recovered, and the similar BAL fluid cell and albumin concentrations in groups 1 and 2, suggest that the dynamics of the instilled saline were equally matched, and that the dilution of epithelial lining fluid was equivalent. Furthermore, the lack of influence of parental smoking on the paediatric alveolar leukocyte profile in the present study is compatible with the previous data from normal children $[3,4]$.

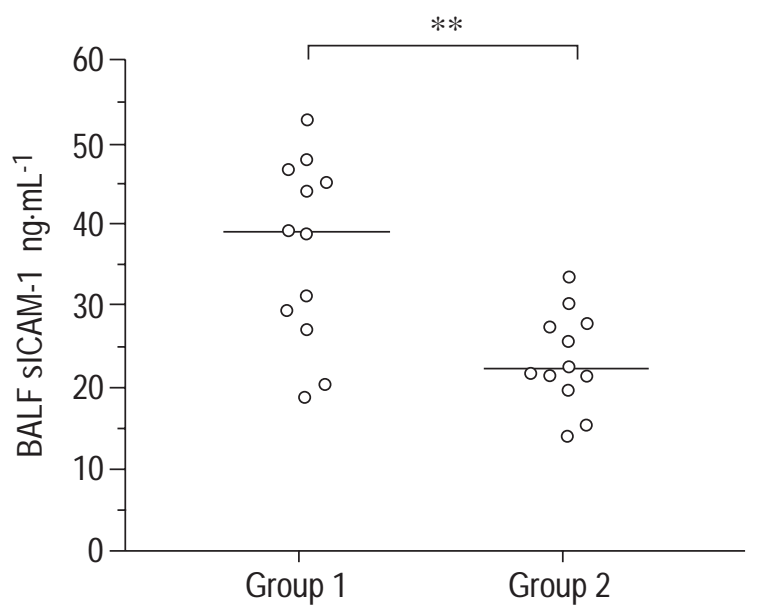

Fig. 1. - Concentrations of soluble intercellular adhesion molecule (sICAM)-1 in the bronchoalveolar lavage fluid (BALF) of children exposed to parental cigarette smoke (group 1) and age- and weightmatched controls (group 2). Bars represent median. ${ }^{*}$ : $\mathrm{p}<0.01$ (Wilcoxon signed-ranks test).
An "objective" marker of environmental cigarette smoke exposure was not used in this study. It is unlikely that parents had misreported their smoking habit for two reasons. Firstly, the smoker(s) were not identified by name, which reduced the pressure for misreporting. Secondly, there is good agreement between parent-reported smoking and the urinary cotinine level in their children $[19,20]$, and in some circumstances, parent-reported smoking may be a better marker of passive exposure than urinary cotinine [21].

Could another variable account for the increased BAL fluid sICAM-1 seen in smoke-exposed children? With the small numbers of subjects available, it was not possible to test the independent effect of smoking in a multivariate model. Potential confounding variables such as ongoing and recent viral infection and atopic disease were controlled for by excluding these children. However, it was not known how many of the study children will develop chronic pulmonary pathology in the future. For example, asthma is associated with increased concentrations of alveolar sICAM-1 [11], and the levels might also be abnormal in the "pre-asthmatic" paediatric lung.

Both the cellular mechanisms for the increased levels of sICAM-1 in the alveoli of smoke-exposed children, and its effect on pulmonary immunocompetence, are unclear. Accumulation of sICAM-1 could either result from increased shedding of ICAM-1 from pulmonary cells, and/or delayed clearance of SICAM-1 from the alveolar space. Upregulation of cell surface ICAM-1 and increased formation of its soluble form is compatible with the observation that cigarette smoke condensate upregulates ICAM-1 on human endothelial cells via the activation of protein kinase $\mathrm{C}$ [22]. Although sICAM-1 is present in the BAL fluid of normal adults [23], and the present study found detectable levels in the normal paediatric lung, its function remains unknown. In general, sICAM-1 per se is a poor inhibitor of ICAM-1 dependent interactions [24], although it does have some immunomodulatory capacity. For example, microspheres coated with recombinant sICAM-1 are capable of specifically inhibiting ICAM-1- $\beta_{2}$-integrin adhesion [24], and pretreatment of endothelial cells with recombinant sICAM-1 reduces leukocyte adherence [25]. Perhaps more importantly, ICAM-1 expression on pulmonary cells is critical to a range of immunological processes, including T-cell activation and neutrophil recruitment [26]. The accumulation of alveolar sICAM-1 in smoke-exposed children may therefore be a marker of upregulation of ICAM-1 on immunocompetent cells within the alveolar milieu.

In conclusion, the present study supports the hypothesis that cigarette smoking by parents is associated with subtle changes in the alveolar microenvironment of their children. Whether the increased levels of soluble intercellular adhesion molecule-1 seen in this study are associated with other changes in pulmonary immune cell function remains to be determined.

\section{References}

1. Strachan DP, Cook DG. Health effects of passive smoking. 1. Parental smoking and lower respiratory illness in infancy and early childhood. Thorax 1991; 52: 905-914.

2. Cook DG, Strachan DP. Parental smoking and prevalence of respiratory symptoms and asthma in school age children. Thorax 1998; 52: 1081-1094. 
3. Heaney LG, Stevenson EC, Turner G, et al. Investigating paediatric airways by non-bronchoscopic lavage: normal cellular data. Clin Exp Allergy 1996; 26: 799-806.

4. Ratjen F, Bredendiek M, Brendel M, Meltzer J, Costabel U. Differential cytology of bronchoalveolar lavage fluid in normal children. Eur Respir J 1994; 7: 1865-1870.

5. Burke WM, Roberts CM, Bryant DH, et al. Smoking induced changes in epithelial lining fluid volume, cell density and protein. Eur Respir J 1992; 5: 780-784.

6. Everson RB, Schreinemachers DM, Devlin RB, Koren HS. Host determinants of cellular and biochemical constituents of bronchoalveolar lavage fluids. Implications for design of epidemiologic studies. Am J Respir Crit Care Med 1994; 149: 899-904.

7. Schaberg T, Lauer C, Lode H, Fischer J, Haller H. Increased number of alveolar macrophages expressing adhesion molecules of the leukocyte adhesion molecule family in smoking subjects. Association with cell-binding ability and superoxide anion production. Am Rev Respir Dis 1992; 146: 1287-1293.

8. McCrea KA, Ensor JE, Nall K, Bleecker ER, Hasday JD. Altered cytokine regulation in the lungs of cigarette smokers. Am J Respir Crit Care Med 1994; 150: 696703.

9. Shijubo N, Imai K, Shigehara $\mathrm{K}$, et al. Soluble intercellular adhesion molecule-1 (ICAM-1) in sera and bronchoalveolar lavage fluid of patients with idiopathic pulmonary fibrosis and pulmonary sarcoidosis. Clin Exp Immunol 1994; 95: 156-161.

10. Takahashi N, Liu MC, Proud D, Yu XY, Hasegawa S, Spannhake EW. Soluble intracellular adhesion molecule 1 in bronchoalveolar lavage fluid of allergic subjects following segmental antigen challenge. Am J Respir Crit Care Med 1994; 150: 704-709.

11. Lee YC, Cheon KT, Rhee YK. Changes of soluble ICAM-1 levels in serum and bronchoalveolar lavage fluid from patients with atopic bronchial asthma after allergen challenge. J Asthma 1997; 34: 405-412.

12. Rothlein R, Mainolfi EA, Czajkowski M, Marlin SD. A form of circulating ICAM-1 in human serum. J Immunol 1991; 147: 3788-3793.

13. Baumer I, Zissel G, Schlaak M, Muller-Quernheim J. Soluble intercellular adhesion molecule-1 (sICAM-1) in bronchoalveolar lavage (BAL) cell cultures and in the circulation of patients with tuberculosis, hypersensitivity pneumonitis and sarcoidosis. Eur J Med Res 1998; 3: 288-294.

14. Beck-Schimmer B, Schimmer RC, Warner RL, et al.
Expression of lung vascular and airway ICAM-1 after exposure to bacterial lipopolysaccharide. Am J Respir Cell Mol Biol 1997; 17: 344-352.

15. Blann AD, Steele C, McCollum CN. The influence of smoking on soluble adhesion molecules and endothelial cell markers. Thromb Res 1997; 85: 433-438.

16. Koumbourlis AC, Kurland G. Nonbronchoscopic bronchoalveolar lavage in mechanically ventilated infants: technique, efficacy, and applications. Pediatr Pulmonol 1993; 15: 257-262.

17. Grigg J, Kleinert S, Woods RL, et al. Alveolar epithelial lining fluid cellularity, protein and endothelin-1 in children with congenital heart disease. Eur Respir J 1996; 9: 1381-1388.

18. Nash MC, Wade AM, Shah V, Dillon MJ. Normal levels of soluble E-selectin, soluble intercellular adhesion molecule-1 (sICAM-1), and soluble vascular cell adhesion molecule-1 (sVCAM-1) decrease with age. Clin Exp Immunol 1996; 103: 167-170.

19. Bakoula CG, Kafritsa YJ, Kavadias GD, et al. Objective passive-smoking indicators and respiratory morbidity in young children. Lancet 1995, 346: 280-281.

20. Irvine L, Crombie IK, Clark RA, et al. What determines levels of passive smoking in children with asthma? Tho$\operatorname{rax}$ 1997; 52: 766-769.

21. Margolis PA, Keyes LL, Greenberg RA, Bauman KE, LaVange LM. Urinary cotinine and parent history (questionnaire) as indicators of passive smoking and predictors of lower respiratory illness in infants. Pediatr Pulmonol 1997; 23: 417-423.

22. Shen Y, Rattan V, Sultana C, Kalra VK. Cigarette smoke condensate-induced adhesion molecule expression and transendothelial migration of monocytes. Am J Physiol 1996; 270: H1624-1633.

23. Southcott AM, Hemingway I, Lorimer S, et al. Adhesion molecule expression in the lung: a comparison between normal and diffuse interstitial lung disease. Eur Respir $J$ 1998; 11: 91-98.

24. Welder CA, Lee DH, Takei F. Inhibition of cell adhesion by microspheres coated with recombinant soluble intercellular adhesion molecule-1. J Immunol 1993; 150: 2203-2210.

25. Kusterer K, Bojunga J, Enghofer M, et al. Soluble ICAM1 reduces leukocyte adhesion to vascular endothelium in ischemia-reperfusion injury in mice. Am J Physiol 1998; 275: G377-380.

26. Carlos TM, Harlan M. Leukocyte-endothelial adhesion molecules. Blood 1994; 84: 2068-2101. 